\title{
BMJ Open Factors associated with non-urgent visits to the emergency department in a tertiary care centre, western Saudi Arabia: cross-sectional study
}

\author{
Saja S Al-Otmy, ${ }^{1}$ Abeer Z Abduljabbar, ${ }^{1}$ Rajaa M Al-Raddadi, ${ }^{2}$ \\ Fayssal Farahat (1) ${ }^{3,4,5}$
}

To cite: Al-0tmy SS, Abduljabbar AZ, Al-Raddadi RM, et al. Factors associated with non-urgent visits to the emergency department in a tertiary care centre, western Saudi Arabia: crosssectional study. BMJ Open 2020;10:e035951. doi:10.1136/ bmjopen-2019-035951

- Prepublication history for this paper is available online. To view these files, please visit the journal online (http://dx.doi. org/10.1136/bmjopen-2019035951).

Received 23 November 2019 Revised 24 April 2020 Accepted 14 July 2020

Check for updates

(C) Author(s) (or their employer(s)) 2020. Re-use permitted under CC BY-NC. No commercial re-use. See rights and permissions. Published by BMJ.

${ }^{1}$ Family medicine resident, King Abdulaziz Medical City, Jeddah, Saudi Arabia

${ }^{2}$ Community Medicine

Department, King Abdulaziz

University, Jeddah, Saudi Arabia

${ }^{3}$ Infection Prevention and Control Department, King Abdulaziz

Medical City, Jeddah, Saudi

Arabia

${ }^{4}$ King Abdullah International Medical Research Center (KAIMRC), Jeddah, Saudi Arabia ${ }^{5}$ College of Medicine, King Saud bin Abdulaziz University for Health Sciences, Jeddah, Saudi Arabia

Correspondence to

Dr Fayssal Farahat;

fmfayssal@gmail.com

\section{ABSTRACT}

Objectives To explore magnitude and factors associated with non-urgent visits to the emergency department (ED) in a tertiary care centre, western Saudi Arabia.

Design A cross-sectional study.

Setting ED of a tertiary care hospital in western Saudi Arabia.

Participants 400 patients, both men and women. Interventions An interview-based questionnaire was administered to a consecutive sample of patients who visited the ED during morning shifts, where primary healthcare centres (PHCs) and outpatient clinics were available.

Primary outcome measure ED visits classified as nonurgent versus urgent (excluding life-threatening conditions) based on the Canadian Triage and Acuity Scale (CTAS). Levels IV and $V$ were classified as non-urgent. Results Majority of the cases were adult (97.3\%) and half of them were women (54.8\%). Non-urgent visits represented $78.5 \%$ among non-life-threatening cases. One-third of the patients (33.8\%) had three visits or more to the ED during the past year. Main reasons for visiting the ED were perception that the condition was urgent (42.0\%), easy access $(25.5 \%)$ and limited resources and services at the PHCs (17.8\%). Patients $40-50$ years old were more likely to have non-urgent visits $(\mathrm{OR}=3.21,95 \% \mathrm{Cl} 1.15$ to 8.98). However, likelihood of non-urgent visits was significantly lower among patients with cancer $(\mathrm{OR}=0.37$, $95 \% \mathrm{Cl} 0.19$ to 0.72 ) and cardiovascular disease ( $\mathrm{OR}=0.43,95 \% \mathrm{Cl} 0.23$ to 0.83 ), and those who live near the hospital ( $\mathrm{OR}=0.49,95 \% \mathrm{Cl} 0.28$ to 0.88$)$.

Conclusions The current study reported overuse of the ED. Enhancement of the primary care services, in concordance with community awareness, is an important component to reduce burden due to non-urgent use of the ED.

\section{INTRODUCTION}

Emergency medicine is a science that deals with diagnosis and treatment of acute cases and accidents. It aims to manage these conditions as quickly as possible to avoid complications and disabilities. ${ }^{1}$

Canadian Triage and Acuity Scale (CTAS) is a method to triage patients who visit the
Strengths and limitations of this study

- Cultural and educational factors are known determinants of emergency department (ED) use that have not been well studied in Saudi Arabia.

- The current study was conducted in a tertiary care referral hospital in Jeddah, which is the second largest city in Saudi Arabia.

- The study reported an experience from a single healthcare centre that serves military personnel and their families, and thus may not represent the status in other governmental or private healthcare sectors.

- Findings on use of ED in this study may be overestimated because of exclusion of patients with lifethreatening conditions (Canadian Triage and Acuity Scale I), although the impact of this potential bias is considered minimal.

- Missing data on some variables (ie, salary and ED waiting time) are considered among study limitations.

emergency department (ED). Based on the urgent condition, patients are prioritised into five levels: resuscitation (level 1) - the physician should see the patient immediately due to conditions that are threats to life or limb; emergent (level 2)-the physician should see the patient within $15 \mathrm{~min}$ due to conditions that are potential threats to life, limb or function; urgent (level 3)-the physician should see the patient within $30 \mathrm{~min}$ due to conditions that could potentially progress to a serious problem requiring emergency intervention; less urgent/semiurgent (level 4)the physician should see the patient within 60 min due to conditions that are related to patient age, distress or possible complications that would benefit from intervention or reassurance; non-urgent (level 5) - the physician should see the patient within $120 \mathrm{~min}$ due to conditions that are non-urgent or may be part of a chronic problem with or without evidence of deterioration. ${ }^{2}$ 
A systematic review of 26 articles about non-urgent visits to EDs in the USA showed that $37 \%$ (range $8 \%-62 \%$ ) of ED visits were non-urgent. Associated factors were easier accessibility compared with other healthcare services, younger age, referral to the ED and lack of knowledge about other options, such as primary care centres. ${ }^{3}$

A study in South Africa found $88.2 \%$ of non-urgent cases were self-referred (only $4.7 \%$ of them were suitable for ED services) and $30.2 \%$ did not have acute complaints. The most common reasons for presenting to the ED were lack of benefit from outpatient clinic (27.5\%), ED has a better treatment $(23.7 \%)$ and unavailability of primary healthcare centres (PHCs) over 24 hours $(22 \%){ }^{4}$

In a Turkish study, ${ }^{5}$ the most common causes for attending ED were to refill medications, request for painkiller or upper respiratory tract infections. The investigators found that patients of non-urgent cases had a misperception that ED services are for any health conditions.

A study in three Ministry of Health (MOH) hospitals in Jeddah, western Saudi Arabia, found that 53\% of patients who visited the ED were non-urgent and $68.5 \%$ of those non-urgent cases have been presented to the ED three to four times per year. A significantly high rate of nonurgent cases did not look for PHCs prior to their visit to the $\mathrm{ED}(58.7 \%$ vs $41.3 \%$ for urgent cases). Most of the non-urgent patients thought that the ED is the first place to seek for in case of sickness. ${ }^{6}$

Jeddah city is the second largest city in Saudi Arabia and serves as an entry point for Hajj pilgrims, with a total population of 4.3 million. Total hospital beds per 10000 population in Jeddah is 7.4 compared with 10 in Riyadh. There are 88 PHCs. ${ }^{7}$ King Abdulaziz Medical City (KAMC), Jeddah, is a tertiary care referral hospital, with a 751-bed capacity, in western Saudi Arabia. The medical city has eight affiliated family medicine and PHCs.

Overcrowded EDs by non-urgent cases is a major problem faced by hospitals in Saudi Arabia. In spite of the availability of several PHCs, patients continued to visit EDs for non-urgent conditions. ${ }^{6}$

With increasing numbers of patients, shortage of staff and inadequate beds in the $\mathrm{ED}$, patients waiting time increased; access to those who need quick care is delayed; and the risk of undesirable outcomes may be accounted. ${ }^{8}$

Identifying reasons for non-urgent use of EDs would help decision makers to set up solutions to improve use of primary care services, reduce medical care cost and reserve the use of EDs for urgent cases that require immediate medical intervention.

The current study aimed to assess the magnitude of nonurgent visits to the ED and to identify factors associated with the non-urgent visits in Jeddah, western Saudi Arabia.

\section{METHODS}

This cross-sectional study was conducted in the ED in KAMC, Jeddah, Saudi Arabia, during the period between April and August 2018.
The ED in KAMC, Jeddah, is divided into four areas: rapid assessment response (RAR), rapid assessment zone (RAZ), intermediate care (IC) area and critical care (CC) area. Each of these areas has a consultant in charge. At the ED triage, patients are classified by trained nurses using the CTAS. Life-threatening conditions (CTAS levels I and II) are transmitted directly to the CC area. If they need admission, they would stay at the IC area until clear stabilisation was confirmed and the proper room is available in the appropriate ward, while CTAS levels III, IV and V are seen in the RAR area by the physician who determines whether the patient is eligible for discharge or if he/she needs further evaluation and assessment to be conducted in the RAZ.

All patients with non-life-threatening conditions who attended the ED at KAMC, Jeddah, during the study period were included in the study.

A consecutive sampling technique was applied to recruit study participants. If a patient refuses to take part in the study, the next patient is approached. Data were collected daily during morning shift from 09:00-16:00, where primary care services and outpatient clinics are available, and patients with non-urgent chronic conditions can visit any of these services.

Assuming prevalence of non-urgent use of ED as $(53 \%),{ }^{8}$ the estimated sample size was 383 at $95 \%$ CI, $5 \%$ margin of error. The study sample size was estimated using the following formula:

$\mathrm{SS}=(\text { Z-score })^{2} \times \mathrm{p} \times(1-\mathrm{p}) /(\text { margin of error })^{2}$

Z-score $=1.96$ for confidence level $95 \%$

A questionnaire was modified based on data from previous studies. ${ }^{6-10}$ The questionnaire has been administered through an interview with patients or their relatives in the ED. The CTAS score of each patient was obtained. The questionnaire included information on (1) patient demographic characteristics (age, gender, nationality, marital status, educational level, current job, salary range, house ownership, place of residence and distance of home from hospital); (2) medical history (main and duration of the current complaint, mode and duration to arrive to the $\mathrm{ED})$; (3) reasons of ED attendance instead of PHCs (the list included difficulty of getting an appointment, easier ED accessibility, thinking his/her case is urgent, too long waiting time in the PHC, dissatisfaction with treatment provided, limited services or resources, lack of experience among medical staff, lack of effective diagnosis, mistrust of PHCs, lack of knowledge of availability of PHC services or other reasons to be specified); (4) nearest PHC to their home or work; and (5) number of ED visits in the past year. Medical service use (laboratory and radiological investigations, performed procedures, medications taken and hospital admission) was assessed.

\section{Patient and public involvement}

No patient was involved.

\section{Statistical analysis}

IBM Statistical Package for Social Sciences V.24 was used to analyse data. Categorical data were analysed using 
$\chi^{2}$ test or Fisher's exact test as appropriate. A KruskalWallis test was used to compare waiting times according to the CTAS level. Multivariate regression analysis was performed to identify factors associated with non-urgent visit to the ED. ORs and 95\% CIs were estimated. The level of significance was determined at 0.05 .

\section{RESULTS}

The total number of patients interviewed during the study period was 400 . The overall response rate was approximately $70 \%$. Non-urgent visits were estimated as $78.5 \%$ among non-life-threatening cases. Women represented $54.8 \%$ and majority of the patients were adults and of Saudi nationality (97.3\%). The mean age in years was 50.3 (SD 19.7) years old (range between 14 and 98 years old). Most of the patients $(69.25 \%)$ were married and about one-quarter $(24.8 \%)$ had university education. Regarding the income, $33.3 \%$ had low income $(<5000$ Saudi Arabian Riyal). More than two-thirds $(69.3 \%)$ had either owned houses or houses paid by work. None of the demographic variables showed statistical significant association with non-urgent visits to the ED, except for age and residency inside Jeddah city. A higher proportion of urgent visits was observed among older patients ( $>50$ years old) $(\mathrm{p}=0.007)$, and those who live inside Jeddah city (near to the ED) also had more urgent visits compared with patients who came from outside the city $(\mathrm{p}=0.04)$ (table 1$)$. Frequency of ED visit during the past year did not show any difference between urgent and non-urgent cases. However, one-third $(33.8 \%)$ of the patients had three visits or more to the ED during the past year (table 1).

The median waiting time in the ED triage area distributed by CTAS score level (II-V) was long among urgent and non-urgent cases $(128,107,163$ and $154 \mathrm{~min}$, respectively) (figure 1).

Diabetes mellitus (DM) and hypertension (HTN) each, represented $36 \%$ of the participants who visited the ED compared with $14.5 \%$ cardiovascular diseases (CVDs), $12.8 \%$ cancer, $11.0 \%$ dyslipidaemia (DLP) and $10.3 \%$ asthma. Urgent visits were significantly higher among patients with cardiovascular conditions or cancer $(\mathrm{p}=0.003$ each $)$ (table 2$)$.

The main reasons of visiting ED instead of PHCs as reported by the patients were patient perception that the condition was urgent (42\%), easier accessibility (25.5\%), limited resources and services in the PHC (17.8\%), and difficulty of getting an appointment $(11.8 \%)$. There were $4.3 \%$ of the participants referred from PHCs to the ED (table 3).

Multivariate regression results are shown in table 4 . Compared with younger age patients, those who are 40-50 years old were more likely to have non-urgent visits ( $\mathrm{OR}=3.21,95 \%$ CI 1.15 to 8.98). However, the likelihood of non-urgent visits was significantly lower among patients who live inside Jeddah city $(\mathrm{OR}=0.49,95 \%$ CI 0.28 to $0.88)$ and those with cancer $(\mathrm{OR}=0.37,95 \%$ CI 0.19 to $0.72)$ or $\mathrm{CVD}(\mathrm{OR}=0.43,95 \%$ CI 0.23 to 0.83$)$.
Table 1 Distribution of demographic characteristics according to the ED visit

\begin{tabular}{|c|c|c|c|}
\hline \multirow[b]{2}{*}{ Variables } & \multicolumn{2}{|l|}{ ED visit } & \multirow[b]{2}{*}{$P$ value } \\
\hline & $\begin{array}{l}\text { Non-urgent } \\
(\mathrm{n}=314,78.5 \%)\end{array}$ & $\begin{array}{l}\text { Urgent } \\
(n=86,21.5 \%)\end{array}$ & \\
\hline \multicolumn{4}{|l|}{ Gender } \\
\hline Male & $139(44.3)$ & $42(48.8)$ & 0.45 \\
\hline Female & $175(55.7)$ & $44(51.2)$ & \\
\hline \multicolumn{4}{|l|}{ Age (years) } \\
\hline$<40$ & 105 (33.4) & $26(30.2)$ & 0.007 \\
\hline $40-50$ & $57(18.2)$ & $5(5.8)$ & \\
\hline$>50$ & $152(48.4)$ & $55(64.0)$ & \\
\hline \multicolumn{4}{|l|}{ Nationality } \\
\hline Saudi Arabian & $306(97.5)$ & $83(96.5)$ & $0.64^{*}$ \\
\hline Non-Saudi Arabian & $8(2.6)$ & $3(3.5)$ & \\
\hline \multicolumn{4}{|l|}{ Marital status } \\
\hline Married & $222(70.7)$ & $55(64.0)$ & 0.31 \\
\hline Divorced & $7(2.2)$ & $5(5.8)$ & \\
\hline Widowed & $31(9.9)$ & $10(11.6)$ & \\
\hline Single & $54(17.2)$ & $16(18.6)$ & \\
\hline \multicolumn{4}{|l|}{ Educational level } \\
\hline Non-educated & $93(29.6)$ & $29(33.7)$ & 0.47 \\
\hline $\begin{array}{l}\text { Primary/ } \\
\text { intermediate }\end{array}$ & $70(22.3)$ & 19 (22.1) & \\
\hline High school & $68(21.7)$ & $22(25.6)$ & \\
\hline University & $83(26.4)$ & $16(18.6)$ & \\
\hline \multicolumn{4}{|l|}{ Job } \\
\hline Student & $19(6.1)$ & $8(9.3)$ & 0.16 \\
\hline Employee & $66(21.0)$ & $12(14.0)$ & \\
\hline Non-employee & $164(52.3)$ & $41(47.7)$ & \\
\hline Retired & $65(20.7)$ & $25(29.1)$ & \\
\hline \multicolumn{4}{|l|}{ Salary (SAR) $\dagger$} \\
\hline$\leq 5000$ & $100(31.9)$ & $33(38.4)$ & 0.30 \\
\hline $5001-10000$ & $38(12.1)$ & $6(7.0)$ & \\
\hline$>10000$ & $58(18.5)$ & $16(18.6)$ & \\
\hline \multicolumn{4}{|l|}{ Home } \\
\hline Owned & 214 (68.2) & $55(64.0)$ & 0.47 \\
\hline Rent & $95(30.3)$ & $28(32.6)$ & \\
\hline Provided by work & $5(1.6)$ & $3(3.5)$ & \\
\hline \multicolumn{4}{|l|}{ Residency } \\
\hline Inside Jeddah city & $204(65.0)$ & $66(76.7)$ & 0.04 \\
\hline Outside Jeddah city & $110(35.0)$ & $20(23.3)$ & \\
\hline \multicolumn{4}{|c|}{ Frequency of ED visit in the past year } \\
\hline None & $121(38.7)$ & $35(40.7)$ & 0.48 \\
\hline Once & $49(15.6)$ & $9(10.5)$ & \\
\hline Twice & $42(13.4)$ & $9(10.5)$ & \\
\hline Three times or more & $102(32.5)$ & $33(38.4)$ & \\
\hline
\end{tabular}

${ }^{*}$ Fisher's exact test.

†Data from 118 and 31 patients, respectively, were missing from the non-urgent and urgent groups.

ED, emergency department; SAR, Saudi Arabian Riyal. 


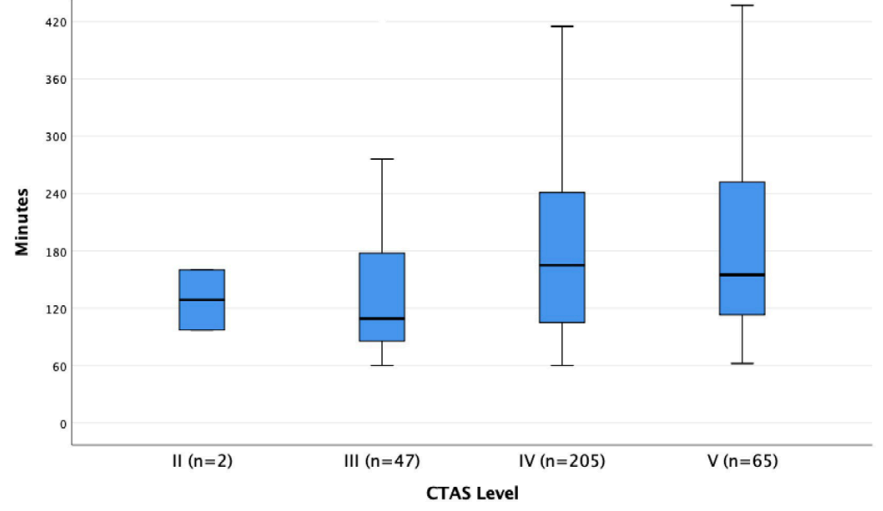

Figure 1 Median waiting time in minutes in the emergency department triage area (Kruskal-Wallis test, $\mathrm{p}$ value=0.001). CTAS, Canadian Triage and Acuity Scale.

Overall imaging investigations were performed in $54.6 \%$ (chest X-rays were done to one-third of the patients, $31.5 \%)$. Majority of patients had laboratory investigations $(75.8 \%)$, where $85.2 \%$ were basic screening (complete blood count (CBC), liver and renal profiles and blood sugar), $79.2 \%$ were $\mathrm{CBC}$ and $51.3 \%$ were troponin test. Procedures were done for $7.2 \%$ (table 5 ).

In the current study, $20.3 \%$ of the patients had documented admission to the hospital, where $59.3 \%$ of them were defined as non-urgent based on the CTAS criteria. However, among the urgent cases, $38.4 \%$ were admitted compared with $15.3 \%$ among the non-urgent cases (table 5).

\section{DISCUSSION}

The current study reported increased non-urgent ED visits in KAMC, Jeddah, during the study period. Our findings are consistent with a similar study in Saudi Arabia where non-urgent visits (CTAS IV-V) represented 75.7\%. ${ }^{11}$ However, it was higher than previous data from Saudi Arabia, which showed $50 \%-60 \%$ of the ED visits were non-urgent. ${ }^{6} 8$ Other studies outside Saudi Arabia have found much lesser rates of non- urgent visits between $10 \%$ and $40 \% .{ }^{3912}$ Due to exclusion of patients with lifethreatening conditions, the current proportion is probably overestimated, although potential bias is considered low, taking into consideration the small percentage of patients with CTAS I and II. The Elkum et al study in a similar hospital reported $0.2 \%$ and $0.6 \%$, respectively, for patients with CTAS I and II. ${ }^{11}$

An almost equal percentage of male and female patients participated in the study. A similar study in a tertiary care hospital in Jeddah, Saudi Arabia, showed that male patients represented more than two-thirds of the ED visits (69\%), and the average age was relatively lower (patients aged 19-40 years old) ${ }^{8}$ However, in concordance with the current study in three $\mathrm{MOH}$ hospitals, female patients represented also half of the cases, although the age of patients was younger compared with the current study (most of them were 16-23 years old). ${ }^{6}$ Factors associated with non-urgent ED visits were being single, age less than 15 years and low income. ${ }^{6}$
Table 2 Distribution of the associated chronic comorbidities according to the ED visit

\begin{tabular}{|c|c|c|c|}
\hline \multirow[b]{2}{*}{ Comorbidities } & \multicolumn{2}{|l|}{ ED visit } & \multirow[b]{2}{*}{ P value* } \\
\hline & $\begin{array}{l}\text { Non-urgent } \\
(n=314,78.5 \%)\end{array}$ & $\begin{array}{l}\text { Urgent } \\
(\mathrm{n}=86,21.5 \%)\end{array}$ & \\
\hline \multicolumn{4}{|l|}{ Diabetes mellitus } \\
\hline Yes & $110(35.0)$ & 34 (39.5) & \multirow[t]{2}{*}{0.44} \\
\hline No & 204 (65.0) & $52(60.5)$ & \\
\hline \multicolumn{4}{|l|}{ Hypertension } \\
\hline Yes & $111(35.4)$ & $33(38.4)$ & \multirow[t]{2}{*}{0.61} \\
\hline No & $203(64.6)$ & 53 (61.6) & \\
\hline \multicolumn{4}{|c|}{ Cardiovascular diease } \\
\hline Yes & $37(11.8)$ & $21(24.4)$ & \multirow[t]{2}{*}{0.003} \\
\hline No & 277 (88.2) & $65(75.6)$ & \\
\hline \multicolumn{4}{|l|}{ Cancer } \\
\hline Yes & $32(10.2)$ & $19(22.1)$ & \multirow[t]{2}{*}{0.003} \\
\hline No & $282(89.8)$ & 67 (77.9) & \\
\hline \multicolumn{4}{|l|}{ Dyslipidaemia } \\
\hline Yes & $32(10.2)$ & $12(14.0)$ & \multirow[t]{2}{*}{0.32} \\
\hline No & $282(89.8)$ & $74(86.0)$ & \\
\hline \multicolumn{4}{|l|}{ Asthma } \\
\hline Yes & $31(9.9)$ & $10(11.6)$ & \multirow[t]{2}{*}{0.63} \\
\hline No & $283(90.1)$ & $76(88.4)$ & \\
\hline
\end{tabular}

Only one case was reported for each of the following conditions: interstitial lung disease, multiple sclerosis, kidney transplant, gastro-oesophageal reflux disease, pulmonary tuberculosis, pernicious anaemia, nephrolithiasis, idiopathic thrombocytopenic purpura, haemophilia, Miller-Dieker syndrome, knee replacement, skin condition, sickle cell disease, thalassemia, sarcoidosis, heart stent, thigh vessel stent, vitamin D deficiency, liver transplant, hepatitis, hypotension, deep vein thrombosis, osteomyelitis, hemiplegia, HIV, Crohn's disease, psoriasis, perioral dermatitis, irritable bowel syndrome, gout, anaemia, autoimmune cholangitis, systemic lupus erythematosus and liver cirrhosis.

${ }^{*} \mathrm{X}^{2}$ test.

ED, emergency department.

However, in the current study, we found that more than half of the patients who visited ED were married and of older age. Similarly, most patients who visited the ED for nonurgent conditions had low income.

The most common chronic diseases among patients who visited the ED in KAMC were diabetes and HTN, then CVDs, cancer, DLP and asthma. Non-urgent visits were less likely among patients with cancer and CVD. In the Dawoud et alstudy, ${ }^{6}$ the most common chronic disease was also diabetes, then HTN and asthma. However, in the Idil et al study, ${ }^{13}$ the most common complaints of the nonurgent cases were muscular pain (25.2\%), then upper respiratory tract symptoms $(19.7 \%)$, although $80.3 \%$ did not have any chronic diseases. The authors found that $17.1 \%$ of non-urgent patients had recurrent ED visits for the same complaints within 2 weeks. 
Table 3 Common reasons for visiting the ED instead of PHCs as reported by the participants

\begin{tabular}{|c|c|c|c|}
\hline \multirow[b]{2}{*}{ Variables } & \multicolumn{2}{|l|}{ ED visit } & \multirow[b]{2}{*}{ P value } \\
\hline & $\begin{array}{l}\text { Non-urgent } \\
(n=314, \\
78.5 \%)\end{array}$ & $\begin{array}{l}\text { Urgent } \\
(\mathrm{n}=86, \\
21.5 \%)\end{array}$ & \\
\hline $\begin{array}{l}\text { Difficulty of getting an } \\
\text { appointment }\end{array}$ & $37(11.8)$ & $10(11.6)$ & 0.97 \\
\hline $\begin{array}{l}\text { Easy accessibility to the } \\
\text { ED }\end{array}$ & $82(26.1)$ & $20(23.3)$ & 0.59 \\
\hline $\begin{array}{l}\text { Think the condition is } \\
\text { urgent }\end{array}$ & $129(41.1)$ & $39(45.3)$ & 0.48 \\
\hline Limited services in $\mathrm{PHC}$ & $61(19.4)$ & $10(11.6)$ & 0.09 \\
\hline Referred from $\mathrm{PHC}$ & $11(3.5)$ & $6(7.0)$ & 0.16 \\
\hline
\end{tabular}

${ }^{*} \mathrm{X}^{2}$ test.

$\mathrm{ED}$, emergency department; PHC, primary healthcare centre.

Bukhari $e t a l^{14}$ reported that the mean ED length of stay among patients in Makkah, Saudi Arabia, was 3.02 hours. Level I patients had the lowest waiting time, while level IV patients had the longest waiting time ( $44 \%$ of patients spent less than 1 hour in the waiting area, and $32.6 \%$ spent 1.0-3.59 hours). The current study reported a relatively lower median waiting time (2.1 hours for level II and 2.6 hours for level V). This waiting time is long compared with other data from Taiwan, for example, where the maximum waiting time in ED was less than 30 min. ${ }^{10}$

Most patients in the current study thought that their conditions were urgent, while others reported easier accessibility, limited resources at the PHC and difficulty getting an appointment as reasons for their choice to visit $\mathrm{ED}$ for their conditions. In the Idil et al study, ${ }^{13}$ the investigators reported easier accessibility and availability of services in the ED for 24 hours. A study by Afilalo $e a^{15}$ reported that $32 \%$ of the patients with non-urgent visits could not get an appointment at PHCs. In the meantime, the O'Brien et al study ${ }^{16}$ found that almost half of the patients $(48 \%)$ who usually seek medical care through ED tried to get a primary care physician. Another study by Steele et $a l^{17}$ listed similar reasons for patients who seek ED for medical care: availability of ED 24 hours and inability to get an early appointment or the walk-in clinic was closed. Also, a significant proportion (about 30\%) of the patients believed that ED offered specialised services.

In the current study, medical service use showed a high percentage of diagnostic and therapeutic interventions. Imaging was performed for more than half of the visiting patients with most of the imaging investigations being chest X-rays. Meanwhile, laboratory investigations were done for a majority of cases, mainly basic screening, and a troponin test was done for half of the cases. In the Dawoud et alstudy, imaging was done for $46.2 \%{ }^{6}$ On the other hand, other studies found a fewer rate of non-urgent ED service use. ${ }^{18-20}$

In spite of the improved PHC services over the past years, several challenges are still discouraging patients from optimally using PHCs, for example, lack of laboratory
Table 4 Multivariate regression analysis of factors associated with likelihood of non-urgent visit to the emergency department

\begin{tabular}{|c|c|c|c|}
\hline Variables & OR & $95 \% \mathrm{Cl}$ & $P$ value \\
\hline Gender, male & 0.91 & 0.55 to 1.52 & 0.73 \\
\hline \multicolumn{4}{|l|}{ Age (years) } \\
\hline$<40$ & 1 & & \\
\hline $40-50$ & 3.21 & 1.15 to 8.98 & 0.03 \\
\hline$>50$ & 0.81 & 0.45 to 1.43 & 0.46 \\
\hline Residency, inside Jeddah city & 0.49 & 0.28 to 0.88 & 0.02 \\
\hline $\begin{array}{l}\text { Limited services in primary } \\
\text { healthcare }\end{array}$ & 0.61 & 0.29 to 1.30 & 0.2 \\
\hline Diabetes mellitus & 1.08 & 0.55 to 2.10 & 0.83 \\
\hline Hypertension & 0.82 & 0.44 to 1.55 & 0.54 \\
\hline Dyslipidaemia & 0.80 & 0.36 to 1.70 & 0.54 \\
\hline Asthma & 0.80 & 0.36 to 1.78 & 0.58 \\
\hline Cardiovascular disease & 0.43 & 0.23 to 0.83 & 0.01 \\
\hline Cancer & 0.37 & 0.19 to 0.72 & 0.003 \\
\hline
\end{tabular}

testing and some imaging facilities (eg, CT equipment) at PHCs; thus, physicians may choose to transfer the patient to the ED to perform such investigations. Transferring patients from PHCs to ED will add extra burden on the $\mathrm{ED}$, in addition to other consequences related to timeconsuming and associated extra cost.

Classifying an ED visit as 'non-urgent' should be based on the patient's symptom severity, but other factors need to be considered, like the proper place of services and availability of substitutional resources for active walk-in cases. ${ }^{21}$ Honigman et al argued that the ED may be a proper place of service for non-urgent problems if other facilities of

Table 5 Distribution of performed imaging or laboratory investigations and hospital admission according to the ED visit

\begin{tabular}{|c|c|c|c|}
\hline \multirow[b]{2}{*}{ Variables } & \multicolumn{2}{|l|}{ ED visit } & \multirow[b]{2}{*}{$P$ value } \\
\hline & $\begin{array}{l}\text { Non-urgent }(n=314 \text {, } \\
78.5 \%)\end{array}$ & $\begin{array}{l}\text { Urgent }(n=86, \\
21.5 \%)\end{array}$ & \\
\hline \multicolumn{4}{|l|}{ Imaging } \\
\hline Yes & $145(46.2)$ & $73(84.9)$ & \multirow[t]{2}{*}{0.001} \\
\hline No & $169(53.8)$ & $13(15.1)$ & \\
\hline \multicolumn{4}{|c|}{ Chest X-ray } \\
\hline Yes & $71(22.6)$ & $55(64.0)$ & \multirow[t]{2}{*}{0.001} \\
\hline No & $243(77.4)$ & $31(36.1)$ & \\
\hline \multicolumn{4}{|c|}{ Laboratory investigation } \\
\hline Yes & $220(70.1)$ & $83(96.5)$ & \multirow[t]{2}{*}{0.001} \\
\hline No & $94(29.9)$ & $3(3.5)$ & \\
\hline \multicolumn{4}{|c|}{ Hospital admission } \\
\hline Yes & $48(15.3)$ & $33(38.4)$ & \multirow[t]{2}{*}{0.001} \\
\hline No & $266(84.7)$ & 53 (61.6) & \\
\hline
\end{tabular}

${ }^{*} \mathrm{X}^{2}$ test.

ED, emergency department. 
medical services are not available to provide timely care to the patient. ${ }^{9}$ It has been reported that cost of care for nonurgent complaints is comparable to outpatient settings. ${ }^{22}$ However, this estimate should be considered in view that the estimated ED cost relied on one visit and did not involve additional services ${ }^{22} 23$ or proportional use of medications, procedures and diagnostic investigations in the outpatient clinic, compared with the ED.

A relatively high proportion of non-urgent cases that required admission has been observed in the current study. Prior studies have found admission rates of nonurgent ED visits up to $6.2 \% .^{152425}$ Similarly, Honigman et $a \hat{\theta}$ reported $4 \%$ admission rate of non-urgent ED cases. In Tsai $e t a l,{ }^{10}$ the admission rate and medical service use was higher in CTAS level I patients, while levels IV and V had the lowest admission rate and services use.

The current study represented data based on a singlecentre experience, which may not represent the status in other governmental or private healthcare sectors in Saudi Arabia. The estimate of non-urgent use is probably inflated due to exclusion of patients with trauma and lifethreatening conditions. Also, some missing information have been reported in some variables (eg, salary).

In conclusion, this study reported a high rate of overuse of the ED in KAMC, Jeddah. Enhancement of the primary care services and community awareness of the need to reduce burden on ED are essential components for the appropriate use of the ED services.

Acknowledgements The authors thank the emergency department in King Abdulaziz Medical City, Jeddah, for their ultimate support during the study data collection.

Contributors SSA and AZA drafted the study proposal and questionnaire, participated in data collection and contributed to writing the first draft of the manuscript. RMA: revised the questionnaire and the manuscript. FF: revised the study proposal and questionnaire, analysed and interpreted the data, and revised final version of the manuscript.

Funding The authors have not declared a specific grant for this research from any funding agency in the public, commercial or not-for-profit sectors.

\section{Competing interests None declared.}

Patient and public involvement Patients and/or the public were not involved in the design, or conduct, reporting or dissemination plans of this research.

\section{Patient consent for publication Parental/guardian consent obtained.}

Ethics approval Ethical approval was obtained from the Institutional Review Board of King Abdullah International Medical Research Center (study number RJ18/018/J). Informed consent was obtained from each participant or accompanying person. All collected data were kept confidential.

Provenance and peer review Not commissioned; externally peer reviewed.

Data availability statement All data relevant to the study are included in the article.

Open access This is an open access article distributed in accordance with the Creative Commons Attribution Non Commercial (CC BY-NC 4.0) license, which permits others to distribute, remix, adapt, build upon this work non-commercially, and license their derivative works on different terms, provided the original work is properly cited, appropriate credit is given, any changes made indicated, and the use is non-commercial. See: http://creativecommons.org/licenses/by-nc/4.0/.

ORCID iD

Fayssal Farahat http://orcid.org/0000-0001-5186-2872

\section{REFERENCES}

1 Hogan TM, Spiegel T. Emergency medicine. In: Geriatrics for specialists, 2016.

2 Lee JY, Oh SH, Peck EH, et al. The validity of the Canadian triage and acuity scale in predicting resource utilization and the need for immediate life-saving interventions in elderly emergency department patients. Scand J Trauma Resusc Emerg Med 2011;19:68.

3 Uscher-Pines L, Pines J, Kellermann A, et al. Deciding to visit the emergency departement for non-urgent conditions: a systematic review of the literature. Am J Manag Care 2013.

4 Becker J, Dell A, Jenkins L, et al. Reasons why patients with primary health care problems access a secondary hospital emergency centre. $S$ Afr Med J 2012;102:800.

5 Şimșek P, Gürsoy A. Turkish health care providers' views on inappropriate use of emergency department: who when and why? Int Emerg Nurs 2016.

6 Dawoud SO, Ahmad AMK, Alsharqi OZ, et al. Utilization of the emergency department and predicting factors associated with its use at the Saudi Ministry of health general hospitals. Glob J Health Sci 2016;8:90-106.

7 Chamber J. Jeddah annual report 2016-2017 Jeddah facts and figures [online]. Available: https://jeg.org.sa/sites/default/files/library/ files/FF-EN-16012018_0.pdf [Accessed 11 Feb 2020].

8 Bakarman MA, Njaifan NK. Assessment of non-emergency cases attending emergency department at King Fahad General Hospital, Jeddah; pattern and outcomes. Life Sci J 2014;11:20-5.

9 Honigman LS, Wiler JL, Rooks S, et al. National study of non-urgent emergency department visits and associated resource utilization. West J Emerg Med 2013;14:609-16.

10 Tsai JC-H, Liang Y-W, Pearson WS. Utilization of emergency department in patients with non-urgent medical problems: patient preference and emergency department convenience. J Formos Med Assoc 2010;109:533-42.

11 Elkum NB, Barrett C, Al-Omran H. Canadian emergency department triage and acuity scale: implementation in a tertiary care center in Saudi Arabia. BMC Emerg Med 2011;11:3.

12 Carret MLV, Fassa ACG, Domingues MR. Inappropriate use of emergency services: a systematic review of prevalence and associated factors. Cad Saude Publica 2009;25:7-28.

13 Idil H, Kilic TY, Toker İbrahim, et al. Non-urgent adult patients in the emergency department: causes and patient characteristics. Turk $J$ Emerg Med 2018;18:71-4.

14 Bukhari H, Albazli K, Almaslmani S, et al. Analysis of waiting time in emergency department of Al-Noor specialist Hospital, Makkah, Saudi Arabia. Open J Emerg Med 2014.

15 Afilalo J, Marinovich A, Afilalo M, et al. Nonurgent emergency department patient characteristics and barriers to primary care. Acad Emerg Med 2004;11:1302-10.

16 O'Brien GM, Stein MD, Zierler S, et al. Use of the ED as a regular source of care: associated factors beyond lack of health insurance. Ann Emerg Med 1997;30:286-91.

17 Steele S, Anstett D, Milne WK. Rural emergency department use by CTAS IV and V patients. Can J Emerg Med 2008.

18 Storm-Versloot MN, Ubbink DT, Kappelhof J, et al. Comparison of an informally structured triage system, the emergency severity index, and the Manchester triage system to distinguish patient priority in the emergency department. Acad Emerg Med 2011;18:822-9.

19 Wuerz RC, Milne LW, Eitel DR, et al. Reliability and validity of a new five-level triage instrument. Acad Emerg Med 2000;7:236-42.

20 Billings J, Parikh N, Mijanovich T. Emergency department use in New York City: a substitute for primary care? Issue Brief 2000:1-5.

21 Mistry RD, Brousseau DC, Alessandrini EA. Urgency classification methods for emergency department visits: do they measure up? Pediatr Emerg Care 2008;24:870-4.

22 Williams RM. The costs of visits to emergency departments. N Engl J Med 1996;334:642-6.

23 Bamezai A, Melnick G, Nawathe A. The cost of an emergency department visit and its relationship to emergency department volume. Ann Emerg Med 2005;45:483-90.

24 Tanabe P, Gimbel R, Yarnold PR, et al. Reliability and validity of scores on the emergency severity index version 3. Acad Emerg Med 2004;11:59-65.

25 van der Wulp I, Sturms LM, Schrijvers AJP, et al. An observational study of patients triaged in category 5 of the emergency severity index. Eur J Emerg Med 2010;17:208-13. 